\title{
Retention of arsenic and selenium compounds present in coal combustion and gasification flue gases using activated carbons
}

\author{
M.A. López-Antón ${ }^{\text {a }}$, M. Díaz-Somoano ${ }^{\text {a }}$, J.L. G. Fierro ${ }^{\text {b }}$ and \\ M.R. Martínez-Tarazona ${ }^{\mathrm{a}^{*}}$ \\ anstituto Nacional del Carbón CSIC, C/ Francisco Pintado Fe, № 26, 33011,Oviedo, \\ Spain

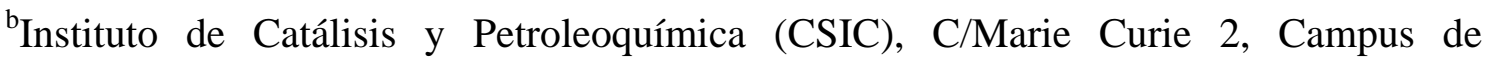 \\ Cantoblanco, 28049-Madrid, Spain \\ *Corresponding author. Telephone +34 98 5119090; Fax +34 985297662 \\ E-Mail address: rmtarazona@incar.csic.es
}




\begin{abstract}
The emission of potentially toxic compounds of arsenic and selenium present in flue gases from coal combustion and gasification processes has led to the need for gas cleaning systems capable of reducing their content. This work is focused on the capture of these elements in activated carbons which have proven to have good retention capacities for mercury compounds in gas phase. Two commercial activated carbons (Norit RBHG3 and Norit RB3) and a carbon prepared via activation of a pyrolysed coal (CA) were tested in simulated coal combustion and gasification atmospheres in a laboratory scale reactor. Arsenic and selenium compounds were retained to different extents on these carbons, retention efficiency depending mainly on the speciation of the element, which in turn depends on the gas atmosphere. Arsenic retention was similar in both combustion and gasification atmospheres unlike selenium retention. Moreover the retention of arsenic was lower than that of selenium.
\end{abstract}

Keywords: activated carbon; arsenic; coal combustion; coal gasification; selenium; 


\section{Introduction}

Arsenic and selenium have been linked to harmful toxicological impacts despite the fact that these elements are essential trace elements for humans and animals. They are among the toxic air metals addressed in the 1990 Clean Air Act Amendments (CAAA). Coal-fired plants for electricity generation are one of the anthropogenic sources of emissions of these elements. Arsenic and selenium concentrations in coal commonly range between 0.5 and $80 \mu \mathrm{g} \mathrm{g}^{-1}$ and 0.2 and $1.4 \mu \mathrm{g} \mathrm{g}^{-1}$, respectively (Swaine, 1990), their mode of occurrence varying for different coals. Commonly, arsenic and selenium are found in iron and sulphur minerals or related with pyrite, but may also be organically associated in low rank coals (Senior et al., 2000; Zeng et al., 2001; Kolker et al., 2000; Bool and Helble, 1995). Upon coal combustion, a large amount of these elements leave the coal matrix and are distributed between the vapour and particulate phases in different proportions, depending on factors such as the initial concentration in the parent coal, the design and operating conditions of the combustion facility, and the particulate control devices. In general, arsenic is more concentrated in particles, whereas selenium remains mainly in gas phase. The concentration of arsenic species in the flue gas depends to a large extent on temperature and chemical interactions with fly ash have been shown to be responsible for partial arsenic retention in particulate phases (Wouterlood and Bowling, 1979). In contrast selenium is one of the most volatile trace elements in coal, second only to mercury and the halide species. Although selenium is also distributed between the vapour and condensed forms, a significant portion of this element escapes into the atmosphere in the form of vapour (Linak and Wendt, 1993; Martínez-Tarazona and Spears, 1996; Andren et al., 1975;Germani and Zoeller, 1988) 
The elemental (As) and oxide forms $\left(\mathrm{As}_{2} \mathrm{O}_{3}\right)$ are considered the most probable arsenic species in the oxidizing flue gas environment of a coal combustion process. However arsenic is much more volatile as $\mathrm{As}_{2} \mathrm{O}_{3}$ than as As and researchers have concluded that arsenic could only be present in the flue gas in the form of an oxide (Dismukes, 1994; Winter et al., 1994). In coal gasification, the most probable species is $\mathrm{As}_{4}$ with traces of arsine $\left(\mathrm{AsH}_{3}\right)($ Clarke and Sloss, 1992; Helble et al., 1996). Selenium can exist in the flue gas in various chemical forms depending on the temperature and flue gas composition. In coal combustion conditions, it is predominantly present in the elemental state (Se) and/or the oxide form $\left(\mathrm{SeO}_{2}\right)$ (Dismukes, 1994; Davinson et al., 1974) whereas in gasification conditions it is found in the hydride form $\left(\mathrm{H}_{2} \mathrm{Se}\right)$ (Clarke and Sloss, 1992; Helble et al., 1996).

Several studies on the retention of trace compounds from flue gases produced by coal combustion and gasification using solid sorbents have been published. These sorbents have been mainly used in two ways; (i) by passing the flue gases through a fixed or fluidised bed of sorbent and (ii) by direct injection of the sorbent as a powder (Mahuli et al., 1997; Ghosh-Dastidav et al., 1996; Gullett and Ragnunathan, 1994). Several solid materials, such as clay minerals, fly ashes, metal oxide mixtures and specially hydrated lime $\left(\mathrm{Ca}(\mathrm{OH})_{2}\right)$ have been tested as sorbents for retaining arsenic and selenium compounds in gases from coal combustion and gasification (Gullett and Ragnunathan, 1994; Ho et al., 1996; Biswas and Wu, 1998). In most of these works, chemisorption is considered to be as one of the probable retention mechanisms. Due to the occurrence of multiple trace elements in flue gases, recent efforts of the research community have been directed towards developing a multifunctional sorbent capable of reducing the emission of most of the pollutants to acceptable limits. Activated carbon offers an attractive option for use as a multifunctional sorbent because it has proved to 
have good retention characteristics for mercury species in gas phase (Krishnan et al., 1994; Ghorishi and Gullett, 1998). However, its effectiveness in controlling selenium, arsenic, and other volatile trace elements still needs to be ascertained (Jadhav et al., 2000). In order to obtain this knowledge, the aim of this work was to determine the capacity of different activated carbons for retaining the arsenic and selenium compounds present in gases from coal combustion and gasification.

\section{Experimental}

Three activated carbons were used, two of which were commercial activated carbons (Norit RB3 and RBHG3). The third was an activated carbon prepared from a low rank coal with a high sulphur content (CA). According to the specifications, RBHG3 was prepared by impregnating RB3 (a peat-based, steam-activated carbon) with sulphur compounds designed to be used for mercury retention at temperatures lower than $80{ }^{\circ} \mathrm{C}$. The activated carbon CA had been prepared in a previous work by activation of a 700 ${ }^{\circ} \mathrm{C}$-semi-coke in a fluidized bed reactor at $750{ }^{\circ} \mathrm{C}$ using steam as gasifying agent (López-Antón, 2004). The CA carbon had a particle size of $0.2-0.5 \mathrm{~mm}$. The commercial activated carbons were employed in their original form, i.e. extruded cylinders of diameter $3 \mathrm{~mm}$ and ground to a size of $0.2-0.5 \mathrm{~mm}$.

The activated carbons were characterized by various methods. The ash and sulfur contents were determined by LECO automatic analyzers. Atomic absorption spectrometry (AAS) was used to determine the elemental composition of the inorganic components of the carbons. The crystalline species in these inorganic components were identified by X-ray Diffraction (XRD) and a morphological study was carried out by Scanning Electron Microscopy (SEM). The porous texture of the activated carbons was determined by $\mathrm{N}_{2}$ and $\mathrm{CO}_{2}$ adsorption isotherms at $77 \mathrm{~K}$ and $273 \mathrm{~K}$, respectively. Pore 
size distributions (PSDs) from the nitrogen adsorption data were obtained by applying the non local density functional theory (NLDFT) procedure (Olivier et al., 1994; Vishnyakov et al., 1999) using software provided by Quantachrome.

Thermodynamic equilibrium calculations using HSC-Chemistry 5.1 software were employed to predict the composition of the chemical species in the gas phase and any theoretically possible reactions with the activated carbon components.

The experimental device used for the retention experiments consisted of a glass reactor fitted with an internal and external tube and heated in two furnaces (Figure 1). As $y$ Se in gas phase were obtained by the evaporation of solid $\mathrm{As}_{2} \mathrm{O}_{3}$ and $\mathrm{Se}^{0}$, respectively. The evaporation temperature of these elements was optimised in order to ensure a continuous and constant amount of trace elements in the combustion and gasification atmospheres, i.e. $0.2 \mathrm{mg} \mathrm{min}^{-1}$. The evaporation temperatures of As and Se were $250^{\circ} \mathrm{C}$ and $400^{\circ} \mathrm{C}$, respectively. The arsenic and selenium concentrations in gas phase were $0.40 \mu \mathrm{g} \mathrm{ml}^{-1}$ in both atmospheres. Concentrations of arsenic and selenium higher than expected in a coal combustion process were used to achieve the maximum retention capacity of sorbents in a short time. The sorbent and element source were placed inside the same internal tube but heated separately in the two furnaces. The temperature of the sorbent bed was $120^{\circ} \mathrm{C}$. Synthetic gas mixtures, typical of coal combustion (15\% $\mathrm{CO}_{2}, \quad 9.2 \% \quad \mathrm{O}_{2}, \quad 0.2 \% \quad \mathrm{SO}_{2}, 6.6 \% \mathrm{H}_{2} \mathrm{O}$ balanced with $\mathrm{N}_{2}$ ) and gasification processes $\left(64 \% \mathrm{CO}, 3.7 \% \mathrm{CO}_{2}, 20.9 \% \mathrm{H}_{2}, 4.0 \% \mathrm{H}_{2} \mathrm{O} 1.0 \% \mathrm{H}_{2} \mathrm{~S}\right.$ balanced with $\mathrm{N}_{2}$ ), were passed through the reactor. These gas mixtures carried the element compound in vapor phase through the sorbent bed at a flow rate of $0.5 \mathrm{~L} \mathrm{~min}^{-1}$. The element retained was determined by analyzing the activated carbon post-retention after passing different amounts of arsenic or selenium through the activated carbon sorbent bed. Evaluation of the retention of arsenic and selenium using sand as the inert material 
in the bed demonstrated the capture of arsenic in combustion and gasification and that of selenium in gasification to be negligible. In the case of Se in combustion $9.7 \%$ of the quantity passed through the sorbent is condensed in the sand. The amount of element condensed in the reactor before it reached the sorbent bed was determined by carrying out a blank experiment, cleaning the reactor using $\mathrm{HNO}_{3}$, and analyzing the element in solution. The element not retained in the sorbent was captured in impingers containing $\mathrm{HNO}_{3} 0.5 \mathrm{~N}$. The quantity of element retained in the sorbent was analyzed by Inductively Coupled Plasma Mass Spectrometry (ICP-MS) and Atomic Absorption Spectrometry-Hydride Generation (AAS-HG) in the case of arsenic and Inductively Coupled Plasma Mass Spectrometry-Hydride Generation (ICP-MS-HG) in the case of selenium, after dissolution in a microwave oven. Retention capacity (milligrams of element per g of sorbent) and efficiency (percentage of element retained) were then evaluated. To determine maximum retention capacity (MRC), a series of experiments were conducted, in which the quantity of the element source was gradually increased until the sorbent was saturated. Post-retention activated carbons were analyzed by Scanning Electron Microscopy coupled to Energy Dispersive X-ray analysis (SEMEDX) and X-ray photoemission spectroscopic (XPS). Desorption experiments were carried out in the same conditions as adsorption, at the same temperature and using the same gas composition (combustion and gasification).

\section{Results and discussion}

The retention of arsenic and selenium in the activated carbons was studied in various conditions related to the characteristics of the sorbent and the different arsenic and selenium species present in typical coal combustion and gasification atmospheres. 
Three important characteristics differentiate the activated carbons used as sorbents: ash content and composition, sulphur content and porous texture (Tables 1-3).

Ash content is similar in both commercial activated carbons, close to $6 \%$, and reaches a value of $30 \%$ in the carbon prepared from coal. Apart from considering the presence of the carbonaceous material that is the active sorbent, the possible effect of the mineral components as a medium of element capture or as a catalyst in the adsorption process should also be considered. Previous works that used inorganic materials such as lime/limestone, fly ashes (Mahuli et al., 1997; Ghosh-Dastidav et al., 1996; López-Antón et al., 2006) demonstrated that arsenic and selenium in gas-phase may be captured in these materials by means of chemical interactions. In the light of this, possible interactions between arsenic and selenium and the inorganic components of the three activated carbons reported in Table 1 were evaluated. What is remarkable from these data is the large proportion of $\mathrm{Fe}_{2} \mathrm{O}_{3}$ and $\mathrm{CaO}$ in $\mathrm{CA}$ that could influence arsenic and selenium retention (Mahuli et al., 1997; Ghosh-Dastidav et al., 1996; DíazSomoano and Martínez-Tarazona, 2002).

With respect to sulphur content and mode of occurrence, RB3 activated carbon was found to contain a small quantity of sulphur ( $0.43 \% \mathrm{wt})$, whereas RBHG3 and CA contained 6.07 and $5.02 \%(\mathrm{wt})$, respectively. The nature and origin of this sulphur is different for each carbon. Although the sulphur content in CA is high as a consequence of its presence in the original coal, it can be expected in a relatively low reactive form, whereas RBHG3 was impregnated by making the surface of the activated carbon a reactive medium for elements capable of reacting with sulphur (López-Antón, 2002). The different mode of occurrence of sulphur in the activated carbons was revealed by characterization using XPS (Figure 2). It was observed that the relative proportions of $\mathrm{S}^{6+}$ and the other forms of sulphur, indistinguishable from XPS $\left(\mathrm{S}^{\circ}+\mathrm{S}^{2-}\right)$, were different 
in each of the three carbons. In CA the proportion of $\mathrm{S}^{6+}$ was the lowest, while in RB3 it was the highest.

The porous texture of RB3 and RBHG3 activated carbons has been described in detail in a previously published work (López-Antón, 2002). The nitrogen adsorption isotherms for the commercial activated carbons belonged to type I of the BDDT classification (typical of microporous solids), type IV playing only a minor role. The nitrogen adsorption isotherm for CA activated carbon was between type I and type IV. It had a narrow type $\mathrm{H} 4$ hysteresis loop, indicating the presence of slit-shaped mesopores. The values for the surface area, total pore volume, equivalent micropore suface area obtained by fitting the Dubinin-Radushkevich (DR) and micropore volume in activated carbons are given in Table 2. These values had a good correlation coefficient (BET) $(r=0.9999)$. The CA activated carbon had a significantly lower specific area value, $310 \mathrm{~m}^{2} \mathrm{~g}^{-1}$ and a lower total pore and micropore volume. The $\mathrm{CO}_{2}$ adsorption isotherms were carried out in the relative pressure interval of $0-0.03$, where only the narrowest micropores are filled. The results for micropore volume obtained by fitting the Dubinin-Radushkevich (DR) and the equivalent micropore suface area are shown in Table 3. When the data for both commercial activated carbons were compared, the parallel decrease in $\mathrm{N}_{2}$ and $\mathrm{CO}_{2}$ surface areas upon impregnation suggests that sulphur loading occurs in a uniform way, with the partial filling of pores of various sizes and especially the larger pores that are accessible to $\mathrm{N}_{2}$ at $77 \mathrm{~K}$ and high relative pressures. The equivalent micropore surface area value obtained from DR for $\mathrm{CO}_{2}$ is lower than the equivalent micropore surface area for $\mathrm{N}_{2}$ in all the activated carbons. These carbons have a well developed microporosity with pores which the $\mathrm{CO}_{2}$ is unable to fill. To complete the study, Figure 3 presents the NLDFT pore distributions for the CA, RB3 and RBHG3 activated carbons. All the samples have a pore 
distribution with most of the pores ranging between 5 and $20 \AA$, CA, however, has a higher proportion of mesopores. A comparison of the commercial activated carbons shows that the micropores of RB3 are smaller than those of RBHG3. It is known that the minimum at $10 \AA$ in the PSD of RB3 is an artifact due to modelling assumptions (Olivier, 1998).

To predict the As and Se species present in gas phase, a theoretical approach based on thermodynamic data in equilibrium was used. According to these equilibrium composition data, $\mathrm{As}_{4} \mathrm{O}_{10}(\mathrm{~g})$ can be expected to be the most stable species at combustion conditions, while in the coal gasification atmosphere at $120{ }^{\circ} \mathrm{C}$, both $\mathrm{As}_{4} \mathrm{~S}_{4}(\mathrm{~g})$ and $\mathrm{As}_{4}(\mathrm{~g})$ can be expected in proportions of $55 \%(\mathrm{v} / \mathrm{v})$ and $45 \%(\mathrm{v} / \mathrm{v})$, respectively. The equilibrium composition for selenium also depends on the gas atmosphere. In the coal combustion atmosphere, $\mathrm{SeO}_{2}(\mathrm{~g})$ would be the only species present in gas-phase, whereas $\mathrm{H}_{2} \mathrm{Se}(\mathrm{g})$ would theoretically form in the coal gasification atmosphere.

Figures 4-5 show the results of the retention experiments for the two elements studied in different conditions. The quantity of element passed through the sorbent (mg element in gas/g sorbet) was plotted against the quantity of element retained in the activated carbons (mg ret/g sorbent). If the curve is fitted onto two straight lines, two parameters can be inferred. One is efficiency, defined as the percentage of element retained (\%E) and the other the maximum retention capacity (MRC). Efficiency was estimated as the slope value of the line corresponding to the unsaturated sorbent. The MRC corresponds to the saturation level of the sorbent. The values for \%E and MRC are presented in Tables 4-5. Each value was calculated as the average of several determinations (between 4 and 8) and the confidence limit of the results is given as the standard deviation. In spite of the different arsenic compositions expected from the 
theoretical data for the combustion and gasification atmospheres, it can be observed that the retention of arsenic in both atmospheres is similar, retention decreasing slightly in the gasification atmosphere. However, in the case of Se, the MRC and the kinetics of the adsorption are higher in the gasification atmosphere. The MRC for arsenic is slightly higher in the CA activated carbon, in spite of the fact that this activated carbon has the lowest surface area, Vt pores and Vmicr (Tables 2-3). The arsenic retention in both commercial activated carbons can be considered similar although their PSD differed between 5-20 $\AA$ (Figure 3). Therefore, the behavior of activated carbons in arsenic retention did not appear to be dependent on porous texture. It is possible then that the mineral components in the CA, approx. 30\% of ashes, might in some way have influenced arsenic retention. In addition, the loss of arsenic from the CA sorbent postretention was lower (Table 6). As already mentioned, interactions with $\mathrm{Ca}$ and Fe particles have been suggested by several authors (Mahuli et al., 1997; Díaz-Somoano and Martínez-Tarazona, 2002) and, in fact, thermodynamic data at equilibrium at 120 ${ }^{\circ} \mathrm{C}$ show that As-Ca/Fe reactions are theoretically possible:

$$
\begin{array}{lll}
6 \mathrm{CaO}+\mathrm{As}_{4} \mathrm{O}_{10}(\mathrm{~g})=2 \mathrm{Ca}_{3}\left(\mathrm{AsO}_{4}\right)_{2} & {[1]} & \mathrm{K}=1.14 \times 10^{150} \\
6 \mathrm{CaCO}_{3}+\mathrm{As}_{4} \mathrm{O}_{10}(\mathrm{~g})=2 \mathrm{Ca}_{3}\left(\mathrm{AsO}_{4}\right)_{2}+6 \mathrm{CO}_{2}(\mathrm{~g}) & {[2]} & \mathrm{K}=1.07 \times 10^{58} \\
2 \mathrm{CaO}+\mathrm{As}_{4}(\mathrm{~g})+6 \mathrm{H}_{2} \mathrm{O}(\mathrm{g})=2 \mathrm{Ca}\left(\mathrm{AsO}_{2}\right)_{2}+6 \mathrm{H}_{2}(\mathrm{~g}) & {[3]} & \mathrm{K}=2.80 \times 10^{40} \\
2 \mathrm{CaCO}_{3}+\mathrm{As}_{4}(\mathrm{~g})+6 \mathrm{H}_{2} \mathrm{O}(\mathrm{g})=2 \mathrm{Ca}\left(\mathrm{AsO}_{2}\right)_{2}+6 \mathrm{H}_{2}(\mathrm{~g})+2 \mathrm{CO}_{2}(\mathrm{~g})[4] & \mathrm{K}=2.50 \times 10^{08}
\end{array}
$$

Similarly, the following thermodynamic Fe-As interactions may occur [5-8]:

$$
\begin{array}{lll}
2 \mathrm{Fe}_{2} \mathrm{O}_{3}+\mathrm{As}_{4} \mathrm{O}_{10}(\mathrm{~g})=4 \mathrm{FeAsO}_{4} & {[5]} & \mathrm{K}=9.29 \times 10^{33} \\
4 \mathrm{FeS}+\mathrm{As}_{4} \mathrm{O}_{10}(\mathrm{~g})+7 \mathrm{O}_{2}(\mathrm{~g})=4 \mathrm{FeAsO}_{4}+4 \mathrm{SO}_{2}(\mathrm{~g}) & {[6]} & \mathrm{K}=1.10 \times 10^{308} \\
4 \mathrm{FeS}+\mathrm{As}_{4}(\mathrm{~g})=4 \mathrm{FeAsS} & {[7]} & \mathrm{K}=3.98 \times 10^{14} \\
4 \mathrm{FeS}+\mathrm{As}_{4} \mathrm{~S}_{4}(\mathrm{~g})+4 \mathrm{H}_{2}(\mathrm{~g})=4 \mathrm{FeAsS}+4 \mathrm{H}_{2} \mathrm{~S}(\mathrm{~g}) & {[8]} & \mathrm{K}=6.00 \times 10^{13}
\end{array}
$$


Of the $\mathrm{Ca} / \mathrm{Fe}$ compounds considered in these reactions, only $\mathrm{CaCO}_{3}$ was identified by XRD, whereas pyrite was identified by SEM-EDX. An analysis by SEMEDX in CA post retention in the combustion atmosphere corroborated the presence of relatively high quantities of arsenic in particles that have high proportions of Fe (Figure 6). Moreover, the theoretically predicted reactions are more favorable in oxidant conditions, which would explain the slightly higher MRC value obtained in the combustion atmosphere (Table 4). Although the presence and mode of occurrence of sulfur is bound to influence the retention of mercury, from the results obtained (Tables 4-5) it can be inferred that the sulfur species do not have any influence on the capture of arsenic and selenium on either of the activated carbons

Reducing the particle size of the sorbent entails a slight increase in retention capacity but a much greater efficiency (Table 4). The capture of arsenic in the commercial activated carbons may involve physical and/or chemical adsorption. Physical adsorption in the solids of high specific area that tend to be devoid of mesopores would explain the desorption of the arsenic retained (Table 6). Loss of arsenic from the RB3 and RBHG3 sorbents post-retention was in the order of $24-30 \%$. However, the desorption of arsenic in CA was lower (7-12\%), which suggests that the interactions in this activated carbon were even stronger, lending support to the theoretically predicted reactions.

In the case of Se, it can be seen (Table 5) that the element speciation as a consequence of the composition of the gas atmosphere has a more influential role in the capture of this element in activated carbons than the differences in the composition and porous texture of the sorbents. Identification of the selenium species in the combustion and gasification atmospheres at $120^{\circ} \mathrm{C}$ was not possible. MRC and especially efficiency were found to be higher in the gasification atmosphere. This may serve to confirm that 
the selenium species in gas-phase are different in both atmospheres as predicted by the thermodynamic data at equilibrium and confirmed by XPS (Figure 7). $\mathrm{Se}^{4+}$ and $\mathrm{Se}^{2-}$ were the oxidation states on the surface of the sorbents post-retention in the combustion and gasification atmospheres, respectively. Particle size, as in the case of arsenic, increases retention efficiency, as the size of the sorbent decreases, especially in the gasification atmosphere (Table 5). The loss of selenium after thermal treatment at 120 ${ }^{\circ} \mathrm{C}$ was close to $15-19 \%$ in commercial activated carbons and $12-15 \%$ in the activated carbon prepared from a coal (Table 6). The slightly greater stability of selenium retained in CA may be due to the fact that the mineral components influence selenium retention. However selenium capture in CA was slightly lower than in the RB3 and RBHG3 carbons. According to previously published works (López-Antón et al., 2006), a chemical reaction between $\mathrm{CaO}$ and/or $\mathrm{FeS}$ wih $\mathrm{H}_{2} \mathrm{Se}$ is possible in a gasification atmosphere. The fact that CA and commercial activated carbons have different textural characteristics and that the precise mechanism of Se/activated carbon interaction could not be inferred from the results of desorption suggests that both chemical and physical adsorption mechanisms might be involved.

The results of this study indicate that activated carbons are able to capture selenium and arsenic present in coal combustion and gasification flue gases to a certain extent. Although the ash content of the activated carbon may influence the amount of arsenic and selenium captured, no correlation between retention and the porous texture of the sorbents was found. The capture of selenium is strongly influenced by the composition of the atmosphere. 


\section{Acknowledgements}

This work was carried out with the financial support of ECSC (7220-ED/095). We are also grateful to our colleagues in ICB (CSIC) R. Juan and C. Ruiz who prepared the CA activated carbon and Amelia Martínez Alonso of INCAR who assisted us in the textural characterization

\section{References}

Andren, A.W., Klein, D.H., Talmi, Y.,1975. Selenium in coal-fired steam plant emissions. Environ. Sci. Technol. 9, 856-858.

Biswas, P., Wu, Y.Ch.,1998. Control of toxic metal emissions from combustors using sorbents. A review J. Air Waste Manage 48, 113-127.

Bool, L.E., Helble, J.J.,1995. A laboratory study of the partitioning of trace elements during pulverized coal combustion. Energ. Fuels 9, 880-887.

Clarke, L.B., Sloss, L.L., 1992. Trace elements-emissions from coal combustion and gasification emissions. IEA Coal Research, London IEACR/49 111pp.

Davinson, R.L., Natusch, D.F.S., Wallace, J.R., Evans, C.A.,1974. Trace elements in fly ash (Depence of concentration on particle size). Environ. Sci. Technol. 8, 1107-1113.

Díaz-Somoano, M., Martínez-Tarazona, M.R., 2002. Retention of trace elements using fly ash in a coal gasification flue gas. J.Chem. Technol. Biotechnol. 77, 396-402.

Dismukes, E. B., 1994. Trace element control in electrostatic precipitators and fabric filter Fuel. Process. Technol. 39, 403-416.

Germani, M.S., Zoeller, W.H., 1988. Vapor-phase concentrations of arsenic, selenium bromine, iodine and mercury in the stack of a coal-fired power plant. Environ. Sci. Technol. 22, 1079-1085. 
Ghorishi, B., Gullett, B.K., 1998. Sorption of mercury species by activated carbons and calcium-based sorbents: effect of temperature, mercury concentration and acid gases. Waste Manage Res. 16, 582-593.

Ghosh-Dastidav, A., Mahuli, S., Agnihotri, R., Fan, L.S., 1996. Selenium capture using sorbent powders: Mechanism of sorption by hydrated lime. Environ. Sci. Technol. 30, 447-452.

Gullett, B.K., Ragnunathan, K., 1994. Reduction of coal-based metal emissions by furnace sorbent injection. Energ. Fuels. 8, 1068-1076.

Helble, J.J., Mojtahedi, W., Lyyranen, J., Jokiniemi, J., Kauppinen, E., 1996. Trace element partitioning during coal gasification. Fuel, 75, 932-939.

Ho, T.C., Ghebremeskel, A.N., Hopper, J.R., 1996. Trace metal capture by various sorbents during fluidised bed coal combustion. Am. Chem. Soc. Div. Fuel Chem. 41, 801-806.

Jadhav, R.A., Agnihotri, R., Gupta, H., Fan, L., 2000. Mechanism of selenium sorption by activated carbon. Can. J. Chem. Eng. 78, 168-174.

Kolker, A., Huggins, F.E., Palmer, C.A., Shah, N., Crowley, S.S., Huffman, G.P., Finkelman, R.B., 2000. Mode of occurrence of arsenic in four US coals Fuel. Process. Technol. 63, 167-178.

Krishnan, S.V., Gullet, B.K., Jozewicz, W., 1994. Sorption of elemental mercury by activated carbons. Environ. Sci. Technol. 28, 1506-1512.

Linak, W.P., Wendt, J.O.L., 1993. Toxic metal emissions from incineration: Mechanisms and control. Prog. Energ. Combust. Sci. 19, 145-185.

López-Antón, M.A., Tascón, J.M.D., Martínez-Tarazona, M.R., 2002. Retention of mercury in activated carbons in coal combustion and gasification flue gases. Fuel Process. Technol. 77-78, 353-358. 
López-Antón, MA., 2004. Retention of Hg, As and Se compounds in gas phase in solid sorbents: Application to the coal combustion and gasification. Thesis. University of Oviedo, Spain.

López-Antón, M.A., Díaz-Somoano, M., Spears, D.A., Martínez-Tarazona, M.R., 2006. Arsenic and selenium capture by fly ashes at low temperature. Environ. Sci. Technol. (in press).

Mahuli, S., Agnihotri, R., Chauk, S., Ghosh-Dastidar, A., Fan, L.S., 1997. Mechanism of arsenic sorption by hydrated lime. Environ. Sci. Technol. 31, 3226-3231.

Martínez-Tarazona, M.R., Spears, D.A., 1996. The fate of trace elements and bulk minerals in pulverized coal combustion in a power station. Fuel Process. Technol. 47, 79-92.

Olivier, J.P., Conkin, W.P.B., Szombathely, M.V., 1994, in Characterization of Porous Solids III (J. Rouquerol, F. Rodríguez-Reinoso, K.S.W. Sing and K.K. Unger, Eds.), p.81. Elsevier, Amsterdam, 1994.

Olivier, J.P., 1998. Improving the models used for calculating the size distribution of micropore volume of activated carbons from adsorption data. Carbon 36, 1469-1472 Senior, C.L., Zeng, T., Che, J., Ames, M.R., Sarofim, A.F., Olmez, I., Huggins, F.E., Shah, N., Huffman, G.P., Kolker, A., Mroczkowski. S., Palmer, C., Finkelman, R., 2000. Distribution of trace elements in selected pulverized coals as a function of particle size and density. Fuel Process. Technol. 63, 215-241.

Swaine, D.J., 1990. Trace elements in coal. Butterworth, London.

Vishnyakov, A., Ravikovitch, P. I., Neimark, A.V., 1999. Molecular level models for $\mathrm{CO}_{2}$ sorption in nanopores. Langmuir 15, 8736-8742 
Winter, R.M., Mallepalli. R.R., Hellem, K.P., Szydlo, S.W., 1994. Determination of As, $\mathrm{Cd}, \mathrm{Cr}$ and $\mathrm{Pb}$ species formed in a combustion environment. Combust. Sci. and Tech. 101, 45-58.

Wouterlood, H.J., Bowling, K.M., 1979. Removal and recovery of arsenious oxide from flue gases. Environ. Sci. Technol. 13, 93-97.

Zeng, T., Sarofim, A.F., Senior, C.L., 2001. Vaporization of arsenic, selenium and antimony during coal combustion. Comb. Flame. 126, 1714-1724. 


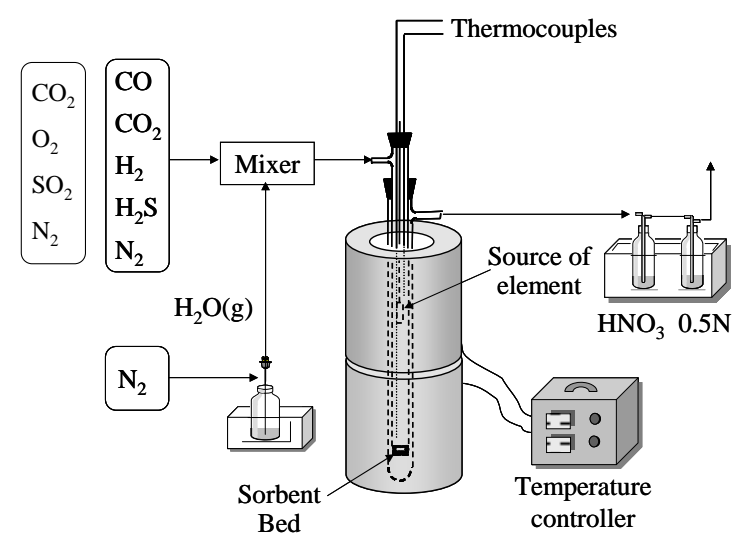

Figure 1. Schematic diagram of the experimental device.
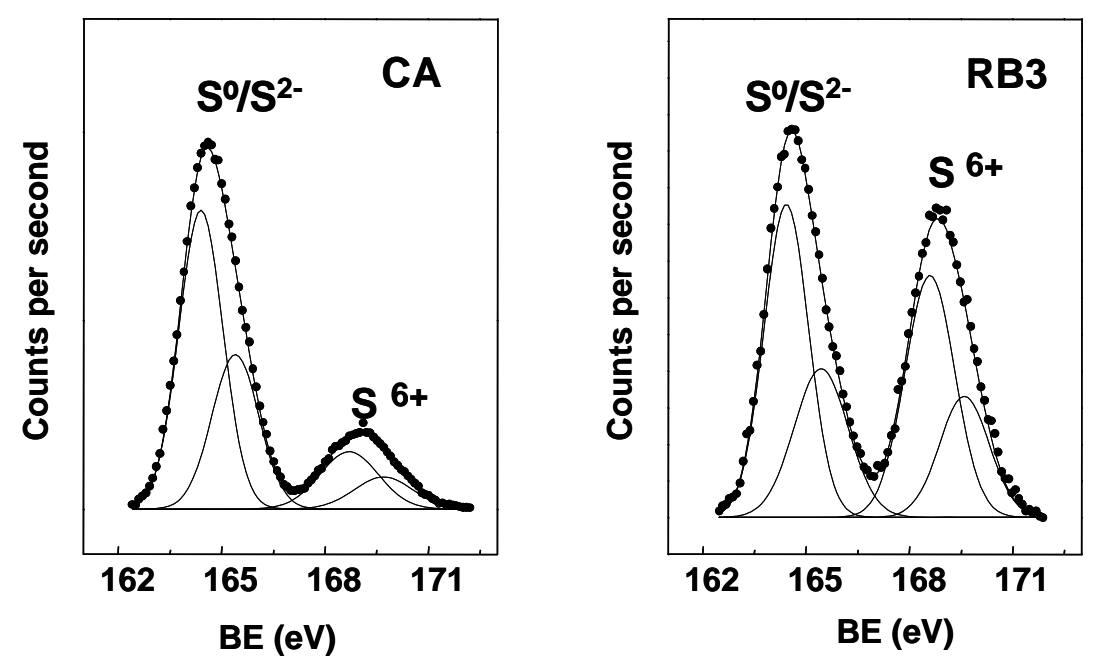

Figure 2. XPS spectrogram of CA and RB3 activated carbons 


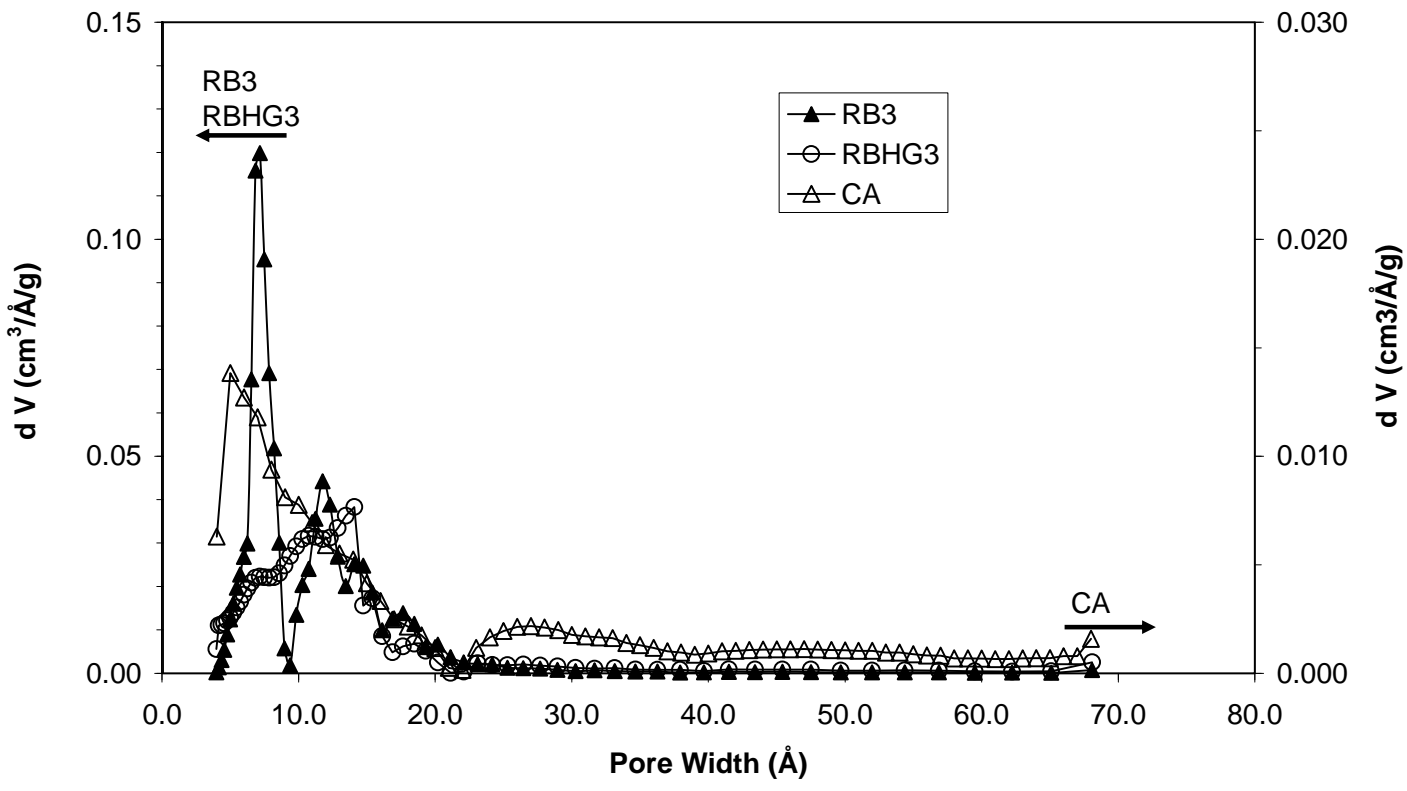

Figure 3. PSDs from the nitrogen isotherms
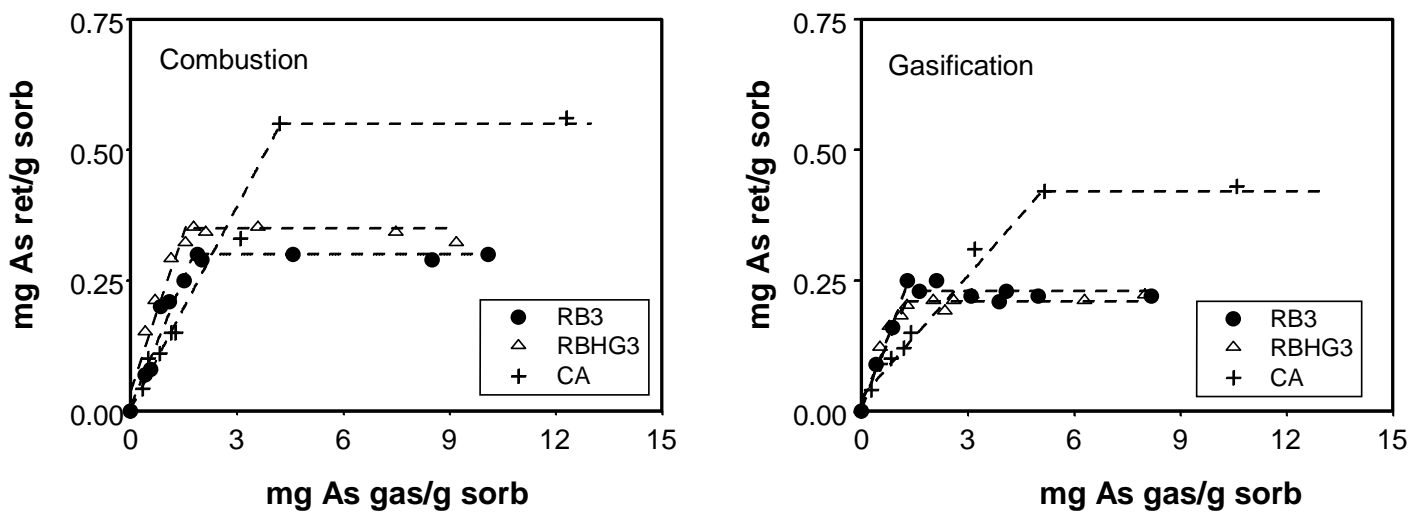

Figure 4. Arsenic retention in activated carbons in (a) the combustion and (b) the gasification atmosphere at the same particle size 

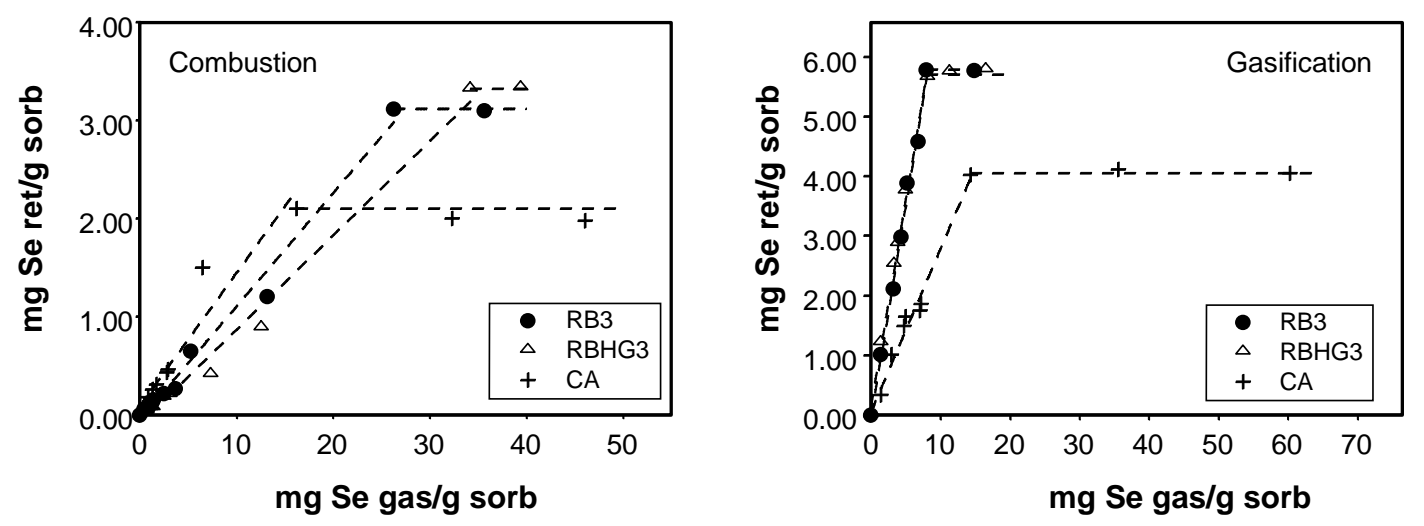

Figure 5. Selenium retention in activated carbons in (a) the combustion and (b) the gasification atmosphere at the same particle size

\section{Counts}

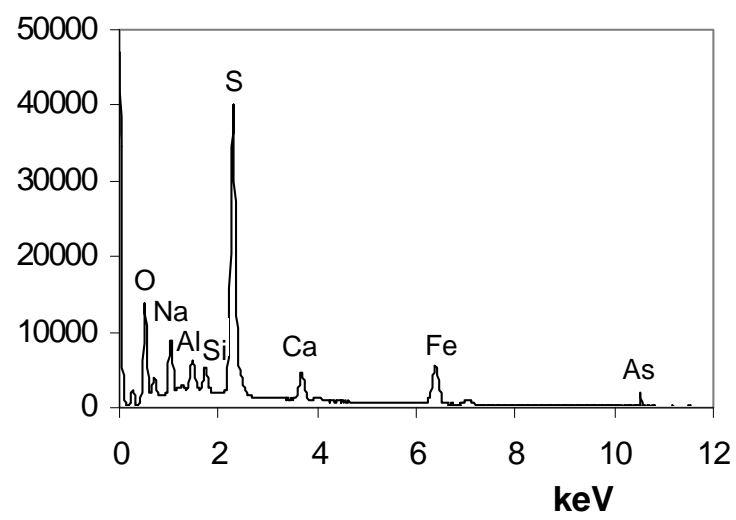

Figure 6. Analysis by EDX of post-retention activated carbon CA obtained in the combustion atmosphere 


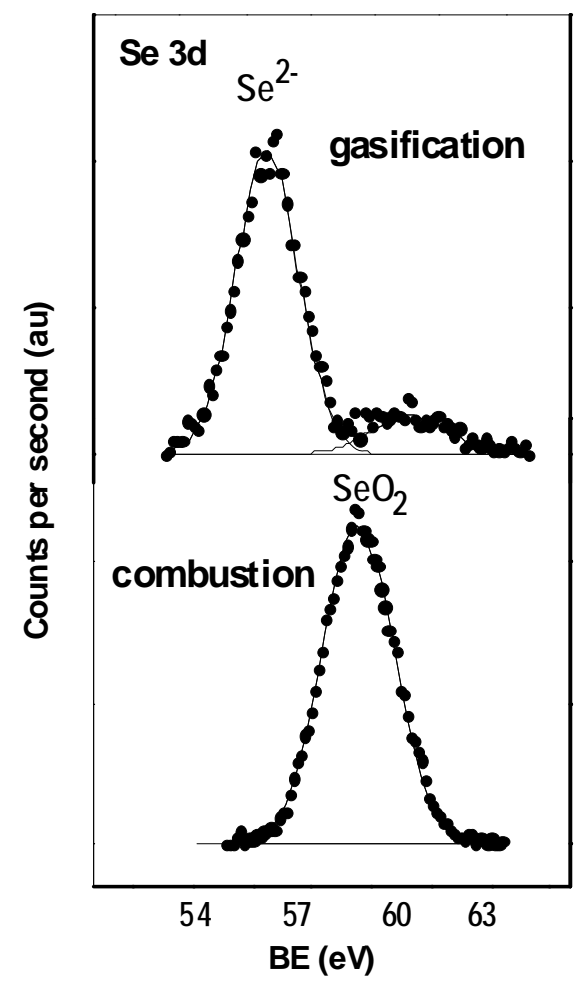

Figure 7. XPS spectrogram of RB3 activated carbon in a combustion and gasification atmosphere 
Table 1. Ash and sulphur contents and analysis of activated carbons

\begin{tabular}{l|ccc}
\hline (\%db) & RB3 & RBHG3 & CA \\
\hline Ash content & 6.04 & 5.51 & 30.0 \\
Sulfur content & 0.43 & 6.07 & 5.02 \\
\hline $\mathrm{SiO}_{2}$ & 2.60 & 1.87 & 9.36 \\
$\mathrm{Al}_{2} \mathrm{O}_{3}$ & 0.32 & 0.30 & 5.37 \\
$\mathrm{Fe}_{2} \mathrm{O}_{3}$ & 0.29 & 0.27 & 10.7 \\
$\mathrm{CaO}$ & 0.52 & 0.48 & 1.82 \\
$\mathrm{MgO}$ & 0.53 & 0.63 & 0.50 \\
$\mathrm{Na}_{2} \mathrm{O}$ & 0.23 & 0.19 & 0.11 \\
$\mathrm{~K}_{2} \mathrm{O}$ & 0.35 & 0.36 & 0.44 \\
$\mathrm{TiO}_{2}$ & $<0.06$ & $<0.06$ & $<0.30$ \\
$\mathrm{P}_{2} \mathrm{O}_{5}$ & 0.24 & 0.23 & --- \\
$\mathrm{SO}_{3}$ & 0.75 & 1.01 & 1.69 \\
\hline
\end{tabular}

\%db; percentage on a dry basis

Table 2. Surface area, total pore volume, DR equivalent micropore suface area and micropore volume in activated carbons

\begin{tabular}{lcccc}
\hline Sorbent & $\begin{array}{c}\mathbf{A} \\
\mathbf{m}^{\mathbf{2}} \mathbf{g}^{\mathbf{- 1}}\end{array}$ & $\begin{array}{c}\text { Vt pores } \\
\mathbf{c m}^{\mathbf{3}} \mathbf{g}^{\mathbf{- 1}}\end{array}$ & $\begin{array}{c}\mathbf{S} \mathbf{D R} \mathbf{~ e q u} \\
\mathbf{m}^{\mathbf{2}} \mathbf{g}^{\mathbf{1}}\end{array}$ & $\begin{array}{c}\text { Vmicr DR } \\
\mathbf{c m}^{\mathbf{3}} \mathbf{g}^{\mathbf{- 1}}\end{array}$ \\
\hline RB3 & 1183 & 0.53 & 1260 & 0.45 \\
RBHG3 & 868 & 0.45 & 1039 & 0.37 \\
CA & 310 & 0.20 & 367 & 0.13 \\
\hline
\end{tabular}

Table 3. Micropores volume and equivalent micropore suface area by DR in activated carbons

\begin{tabular}{lcc}
\hline Sorbent & $\begin{array}{c}\text { Vmicr DR } \\
\mathbf{c m}^{\mathbf{3}} \mathbf{g}^{-\mathbf{1}}\end{array}$ & $\begin{array}{c}\text { S DR } \mathbf{~ e q u} \\
\mathbf{~ m}^{\mathbf{2}} \mathbf{g}^{-\mathbf{1}}\end{array}$ \\
\hline RB3 & 0.37 & 1009 \\
RBHG3 & 0.30 & 830 \\
CA & 0.10 & 276 \\
\hline
\end{tabular}


Table 4. Retention of arsenic from $\mathrm{As}_{2} \mathrm{O}_{3}$ evaporation, in the combustion and gasification atmospheres at $120^{\circ} \mathrm{C}$.

\begin{tabular}{|c|c|c|c|c|c|}
\hline \multirow[b]{2}{*}{ Sorbent } & \multirow[b]{2}{*}{$\begin{array}{c}\text { Particle size } \\
\text { (mm) }\end{array}$} & \multicolumn{2}{|c|}{ Combustion } & \multicolumn{2}{|c|}{ Gasification } \\
\hline & & $\begin{array}{l}\text { MRC } \\
\text { mg g }^{-1}\end{array}$ & $\% \mathrm{E}$ & $\begin{array}{l}\text { MRC } \\
\text { mg g }^{-1}\end{array}$ & $\% \mathbf{E}$ \\
\hline \multirow{2}{*}{ RB3 } & 3 & 0.29 & $7 \pm 2$ & 0.19 & $8 \pm 2$ \\
\hline & $0.2-0.5$ & 0.30 & $17 \pm 2$ & 0.23 & $20 \pm 2$ \\
\hline \multirow{2}{*}{ RBHG3 } & 3 & 0.25 & $10 \pm 2$ & 0.21 & $6 \pm 2$ \\
\hline & $0.2-0.5$ & 0.35 & $26 \pm 7$ & 0.21 & $18 \pm 3$ \\
\hline CA & $0.2-0.5$ & 0.56 & $14 \pm 3$ & 0.43 & $13 \pm 3$ \\
\hline
\end{tabular}

Table 5. Retention of selenium from Se evaporation, in combustion and gasification atmospheres at $120^{\circ} \mathrm{C}$.

\begin{tabular}{lccccc}
\hline \multirow{2}{*}{ Sorbent } & $\begin{array}{c}\text { Particle size } \\
(\mathbf{m m})\end{array}$ & $\begin{array}{c}\text { MRC } \\
\mathbf{m g ~ g}^{-\mathbf{1}}\end{array}$ & $\mathbf{\% E}$ & $\begin{array}{c}\text { MRC } \\
\mathbf{m g ~ g}^{-\mathbf{1}}\end{array}$ & $\mathbf{\%}$ \\
\hline \multirow{2}{*}{ RB3 } & 3 & 3.02 & $9 \pm 3$ & 4.85 & $44 \pm 8$ \\
& $0.2-0.5$ & 3.11 & $10 \pm 2$ & 5.78 & $70 \pm 3$ \\
\hline \multirow{2}{*}{ RBHG3 } & 3 & 3.27 & $10 \pm 2$ & 4.59 & $46 \pm 10$ \\
& $0.2-0.5$ & 3.33 & $6 \pm 1$ & 5.73 & $76 \pm 5$ \\
\hline CA & $0.2-0.5$ & 2.03 & $18 \pm 4$ & 4.06 & $29 \pm 4$ \\
\hline
\end{tabular}

Table 6. Percentages of element lost in the desorption experiments

\begin{tabular}{lcccc}
\hline \multirow{2}{*}{ Sorbent } & \multicolumn{2}{c}{ Combustion (\%) } & \multicolumn{2}{c}{ Gasification (\%) } \\
\cline { 2 - 5 } & As & Se & As & Se \\
\hline RB3 & 25 & 17 & 30 & 19 \\
RBHG3 & 29 & 17 & 24 & 15 \\
CA & 7 & 15 & 12 & 12 \\
\hline
\end{tabular}

